\title{
Article \\ A Compensated Peak Current Mode Control PWM for Primary-Side Controlled Flyback Converters
}

\author{
Chia-Hsuan $\mathrm{Wu}^{1}$, Guan-Rong Huang ${ }^{2}$, Cheng-Chih Chou ${ }^{3,4}{ }^{\mathbb{D}}$, Ching-Ming Lai ${ }^{1} \oplus$ and Liang-Rui Chen ${ }^{3, *}$ \\ 1 Department of Electrical Engineering, National Chung Hsing University, Taichung 402, Taiwan; \\ swdemperor@hotmail.com (C.-H.W.); pecmlai@gmail.com (C.-M.L.) \\ 2 Universal Global Scientific Industrial Co., Ltd., Nantou County 542, Taiwan; gr_huang@usiglobal.com \\ 3 Department of Electrical Engineering, National Changhua University of Education, Changhua 50074, Taiwan; \\ chou@itri.org.tw \\ 4 Green Energy and Environment Research Laboratories, Industrial Technology Research Institute, \\ Hsin-chu 31057, Taiwan \\ * Correspondence: Irchen@cc.ncue.edu.tw
}

Citation: Wu, C.-H.; Huang, G.-R.;

Chou, C.-C.; Lai, C.-M.; Chen, L.-R. A

Compensated Peak Current Mode

Control PWM for Primary-Side

Controlled Flyback Converters.

Energies 2021, 14, 7458.

https://doi.org/10.3390/en14227458

Academic Editor: Federico Barrero

Received: 12 October 2021

Accepted: 1 November 2021

Published: 9 November 2021

Publisher's Note: MDPI stays neutral with regard to jurisdictional claims in published maps and institutional affiliations.

Copyright: (c) 2021 by the authors. Licensee MDPI, Basel, Switzerland. This article is an open access article distributed under the terms and conditions of the Creative Commons Attribution (CC BY) license (https:// creativecommons.org/licenses/by/ $4.0 /)$.

\begin{abstract}
In this paper, a feedback compensator (FBC) and a Feedforward compensator (FFC) are proposed to construct a novel compensated peak current mode control pulse width modulation (CPC-PWM) for primary-side controlled flyback converters. Using the proposed FBC, the PWM duty cycle of an abnormal operating flyback converter would be descended to limit the output current for reducing power dissipation. Using the proposed FFC, the effect of delay time would be descended to reduce the over-flow current for increasing the current accuracy. In this paper, the operating principle and mathematical model are described and analyzed. Then, the component values are well designed to satisfy the electrical specifications. Finally, a prototype is designed and realized to access system performance. The experimental results show that the proposed CPC-PWM can validate in a wide input voltage range and output short conditions, which also has good current accuracy and reduces power dissipation by about $68 \%$.
\end{abstract}

Keywords: feedback compensator; feedforward compensator; flyback converter

\section{Introduction}

Because the flyback converter has a simple structure and does not require a secondary side output inductor, it has considerable advantages in size and cost. Based on the above advantages, the flyback converter is widely used in low power applications [1-16] —especially in LED lighting [8-10] and battery balancing control [11-16] to show its many advantages. With the advancement of digital technology and the cost of microcontrollers has dropped significantly. The control scheme of flyback is also moving towards digital control to obtain higher performance [17-20]. Since the flyback converter is an isolated converter, the output voltage and current are traditionally regulated by utilizing the secondary-side regulation (SSR). Usually, SSR is mainly constructed by a photocoupler. The photocoupler feedback circuit causes above $10 \%$ of the power losses at standby conditions. Recently, primaryside regulation (PSR) flyback converter (i.e., primary-side controlled flyback converter) becomes an important technology due to lower cost and standby power losses [1,17-25]. The primary-side controlled flyback converter stores energy on the transformer when the power switch is $\mathrm{ON}$ and releases the energy on the transformer to the load when the power switch is OFF. It is known that this topology is a constant power output. Based on the constant power output characteristics, when the output voltage of the flyback converter drops due to the load, the output current must increase. When the output voltage of the flyback converter keeps dropping, the current keeps increasing until the current is infinite, causing the problem of components burning. At the same output power, the higher input voltage results in a lower input current. On the contrary, the lower input voltage will result 
in a higher input current. This means that different power losses are caused by different input voltages, so a larger rated component must be selected in the circuit design to meet the range under various conditions.

As shown in Figure 1, the conventional flyback converter has primary side peak current detection overcurrent protection. Because the primary-side peak current detection protection point voltage $V_{\text {LIMIT }}$ is a fixed value, and the flyback converter working in Discontinuous Conduction Mode (DCM) has a constant power output as shown as [22]

$$
P_{O}=\frac{1}{2} \cdot L_{P} \cdot f_{S W} \cdot I_{P}^{2} \cdot \eta
$$

where $L p, f s w, I p$ and $\eta$ are the primary side inductance, switching frequency, primary side peak current, and flyback conversion efficiency, respectively.

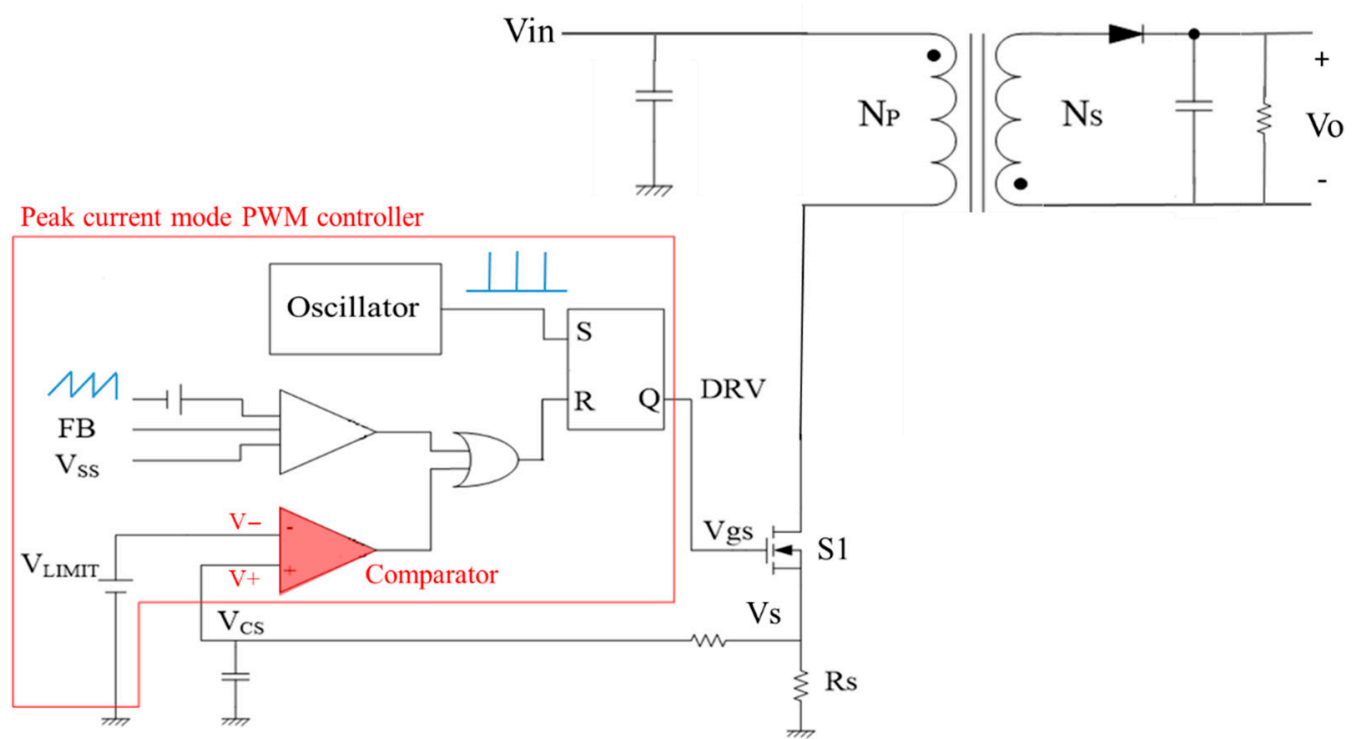

Figure 1. A typical flyback converter with primary side peak current mode control.

When the load on the output terminal becomes larger and larger, the output voltage becomes lower. At this time, the output current will still be larger and larger as shown in Equation (2). Therefore, the current rating of the part needs to be selected with a larger specification, just to meet the protection application.

$$
I_{O}=\frac{1}{2} \cdot L_{P} \cdot f_{S W} \cdot I_{P}^{2} \cdot \eta \cdot \frac{1}{V_{O}}
$$

In order to overcome the above-mentioned problem, two methods were proposed and used in converters. In this first method, a current detection resistor $R_{\text {sense }}$ is connected in series with the current loop at the output end to convert the current signal into a voltage signal. Then, use the comparison circuit or the current monitor IC to judge whether the overcurrent condition is reached. If the overcurrent condition is satisfied, turn off the synchronous rectification switch. Another method is to connect a current detection resistor $R_{\text {sense }}$ in series with the ground current loop at the output end to convert the current signal into a voltage signal. Then, use the comparison circuit or the current detection IC to determine whether the overcurrent condition is occurring. If the condition is satisfied, the primary switch PWM duty is adjusted through the photocoupler control-to make the entire power supply achieve the functions of stability and overload protection. With these two methods, only a current detection resistor $R_{\text {sense }}$ and comparison control circuit or current monitor IC are needed to achieve the purpose of current detection and protection. However, the current detection resistor $R_{\text {sense }}$ is connected in series with the output main circuit. Because the current is large, in order to avoid excessive power loss, the current 
detection resistor is usually very small. The current detection resistance $R_{\text {sense }}$ is generally between several $\mathrm{m} \Omega$ to tens of $\mathrm{m} \Omega$, depending on the output current. Therefore, the converted voltage signal is about tens of $\mathrm{mV}$ and hundreds of $\mathrm{mV}$. The accuracy of such a small voltage signal is obviously insufficient for judgment and control. In addition, the power loss caused by the current detection resistor $R_{\text {sense }}$ under heavy load is inevitable.

In a typical primary-side controlled flyback converter, a sensing resistor $R_{S}$ is used to convert the current on the primary side into a voltage $V_{S}$ and compares it with the reference voltage $V_{\text {LIMIT }}$ of the controller. When the sensing voltage $V_{S}$ is greater than the reference voltage $V_{\text {LIMIT }}$, the comparator is activated to turn off the power switch. Unfortunately, in actual applications, due to the stray capacitance inside the semiconductor device, a fixed logic drive delay is caused. When the input voltage is high, the current slope $m=\frac{V_{\text {in }}}{L_{P}}$ on the primary side becomes steeper. Due to the delay in the response time of the comparators, logic gates, and components, the power switch cannot be turned off immediately when the sensing voltage $V_{S}$ is greater than $V_{\text {LIMIT }}$. As a result, the primary side current still maintains a fixed slope rise, and the overflow current $\Delta I_{P}$ occurs and can be shown as [22]

$$
\Delta I_{P}=\frac{V_{\text {in }}}{L_{P}} \cdot t_{\text {delay }}
$$

where $t_{\text {delay }}$ is the delay time that is the amount delay times of the comparators, logic gates, and other components.

Figure 2 shows a schematic diagram of overflow current $\Delta I_{P}$ changes caused by signal delay under traditional peak current mode control. It can be seen that a higher input voltage $V_{\text {in }}$ has a larger overflow current $\Delta I_{P}$ than a lower input voltage. This leads to a significant difference. When the input voltage is higher, the power that can be provided to the load is higher, and vice versa. This is one of the main reasons affecting line regulation of flyback converter.

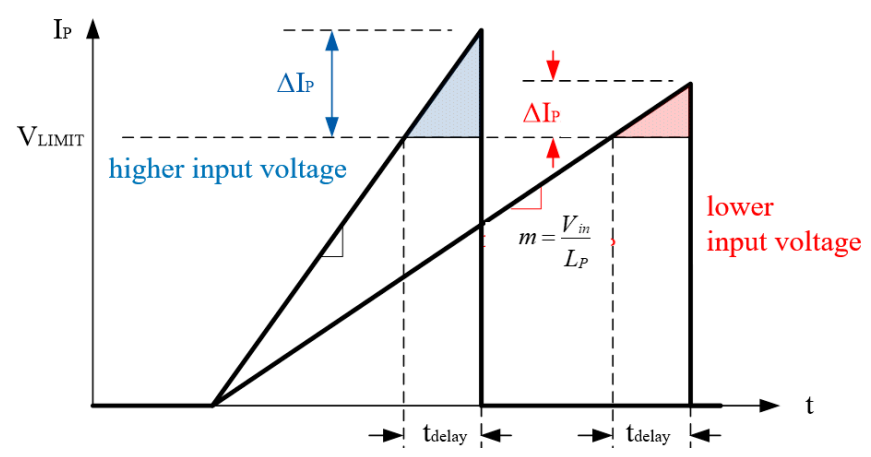

Figure 2. Overflow current with different input voltage.

In order to solve the above problem, many methods and techniques were proposed. The amount of overflow current $\Delta I_{P}$ can be estimated by using the change of current in the same $t_{\text {dealy }}$ time. According to this estimated value to modify the PWM, the influence of $t_{\text {dealy }}$ can be reduced [21]. Furthermore, the CS sample-and-hold circuit is used to measure primary side peak current $I_{p}$. Then, by calculating the average current, a compensation control method that is theoretically unaffected by $t_{\text {dealy }}$ can be obtained [22]. Another method is to measure the mid-point current (i.e., average current) and use the average current control method, which can effectively reduce the influence of $t_{\text {dealy }}$ and increase the accuracy of the output current [23-25]. Recently, digital technology is also used to directly measure $t_{\text {dealy }}$. Finally, $t_{\text {dealy }}$ is compensated to obtain accurate output current $[17,20]$.

Although the above methods can be used to reduce the impact of $t_{\text {dealy }}$. However, when an overload occurs and the output voltage is reduced, the output current cannot be suppressed. Therefore, the current rating of the components needs to be selected with a larger specification, just to meet the protection application. In order to solve this 
problem, a Compensated Peak Current mode controlled PWM (CPC-PWM) for primaryside controlled flyback converters working in DCM is proposed in this paper. In the proposed CPC-PWM, the input voltage $V_{\text {in }}$ is sensed and can be used to compensate for the control signal delay to reduce the overflow current $\Delta I_{P}$ to improve line regulation. In addition, the current limiting by voltage feedback scheme $[26,27]$ is referenced. The output voltage $V_{\text {out }}$ of flyback is sensed and be used to compensate PWM to suppress the overload current.

\section{System Description}

In order to suppress the output current $I_{0}$ of the flyback converter during overload protection, the feedback compensator (FBC) is proposed in this paper. The inherent characteristics of the flyback converter output voltage $V_{\text {out }}$ can be used to detect and adjust the PWM duty. Figure 3 shows the waveforms of a primary-side controlled flyback with FBC control working in DCM. As shown in Figure 3, when the output voltage $V_{\text {out }}$ drops, the power switch duty cycle needs to be reduced to suppress the output current $I_{o}$. This means that the PWM duty cycle $D_{a}$ during abnormal operation should be much smaller than the PWM duty cycle $D_{n}$ during normal operation. The amount of this output voltage drop $\Delta V_{\text {out }}$ is the difference between the rated output voltage $V^{*}$ and the output voltage $V_{\text {out }}$. Thus, the input voltage of the negative terminal of the comparator $V$-will be compensated by the amount of this output voltage drop and written as:

$$
V-=V_{\text {LIMIT }}-k \cdot \Delta V_{\text {out }}=V_{\text {LIMIT }}-k\left(V^{*}-V_{\text {out }}\right)
$$

where $k$ is a positive constant. A larger $k$ means a smaller duty cycle $D_{a}$ is obtained. Equation (4) can be rewritten as:

$$
V-=k_{1} \cdot V_{L I M I T}+k_{2} \cdot V_{\text {out }}-k_{3}
$$

where $k_{1}, k_{2}$, and $k_{3}$ are positive constant. It can be seen from (5) that when the output voltage $V_{\text {out }}$ drops more, the voltage $V$ - becomes smaller. This reduces the PWM duty cycle and achieves the purpose of suppressing the output current $I_{0}$.

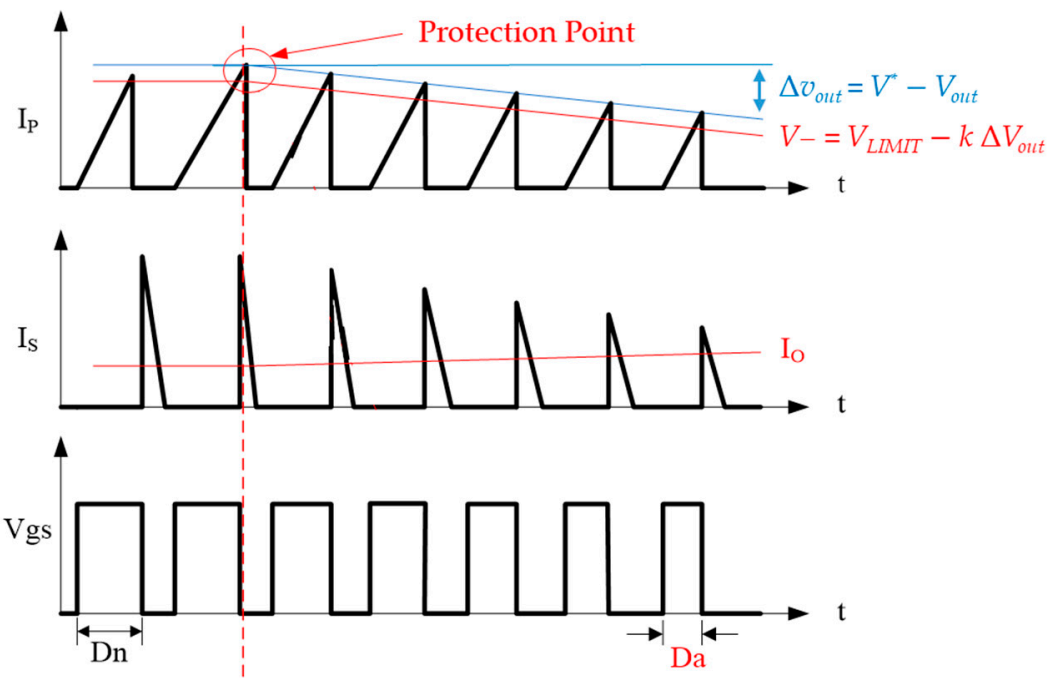

Figure 3. Waveform diagrams of a primary-side controlled flyback with FBC control working in DCM.

Figure 4 shows the theory expected V-I curves of a flyback with and without FBC. Comparing the V-I curves of the traditional method and the proposed method, the output current of the proposed method is much lower. It means that there is no need to choose a power component with a larger current rating. In this way, the power consumption 
problem caused when the output load is increased or short-circuited can be suppressed, and the components with larger specifications can be avoided.

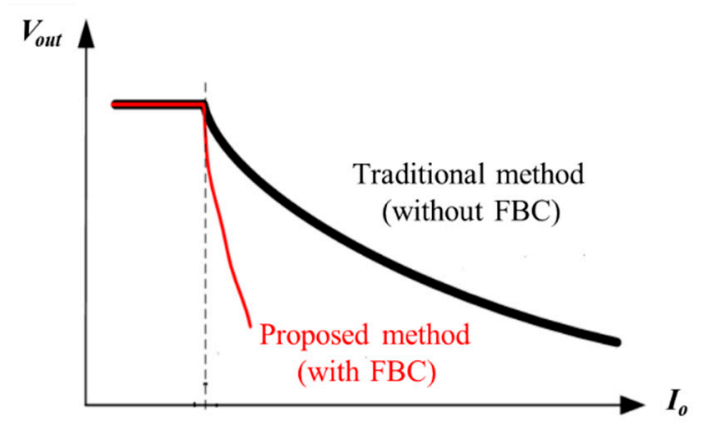

Figure 4. V-I curve of the traditional method and the proposed method.

In order to suppress the overflow current $\Delta I_{P}$ of the flyback converter, the FeedForward Compensator (FFC) is proposed in this paper. The input voltage $V_{\text {in }}$ of the flyback converter is detected and used to adjust the PWM duty, since the overflow current $\Delta I_{P}$ is proportional to the input voltage $V_{\text {in }}$ shown as (3). Figure 5 shows waveforms of a primary-side controlled flyback with FFC control working in DCM. As shown in Figure 5, the input voltage of the positive terminal $V+$ of the comparator is extract added by $k^{\prime} V_{\text {in }}$ as written as:

$$
V+=V_{S}+k^{\prime} \cdot V_{i n}
$$

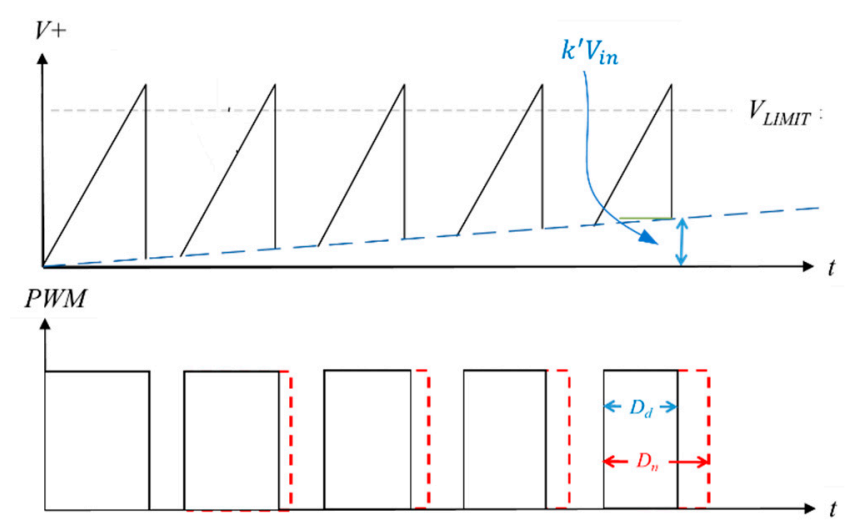

Figure 5. Waveforms of a primary-side controlled flyback with FFC control working in DCM.

Equation (6) can be rewritten as:

$$
V+=k_{4} \cdot V_{S}+k_{5} \cdot V_{\text {in }}
$$

where $k_{4}$ and $k_{5}$ are positive constant. It is clear that when the input voltage $V_{\text {in }}$ increases, the voltage $V+$ becomes larger. When $V+$ becomes larger, the power switch $S 1$ will be turned off early. When (8) is held, the overflow current $\Delta I_{P}$ caused by $t_{\text {delay }}$ is eliminated.

$$
\frac{k_{5}}{k_{4}}=\frac{t_{\text {delay }} \cdot R_{S}}{L_{P}}
$$

Based on the above discussion, the block diagram of the proposed CPC-PWM controller mentioned in this paper can be drawn as Figure $6 \mathrm{~b}$. Compared with the traditional peak current mode control PWM shown in Figure 6a, we can see that the FBC is added, thereby achieving the purpose of suppressing the output protection current. On the other hand, the FFC is also added, thereby suppressing the purpose of the overflow current $\Delta I_{P}$. 


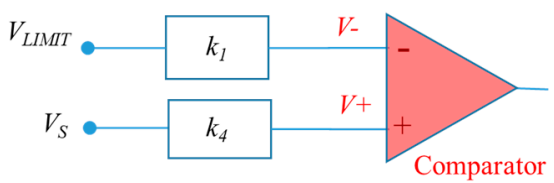

(a)

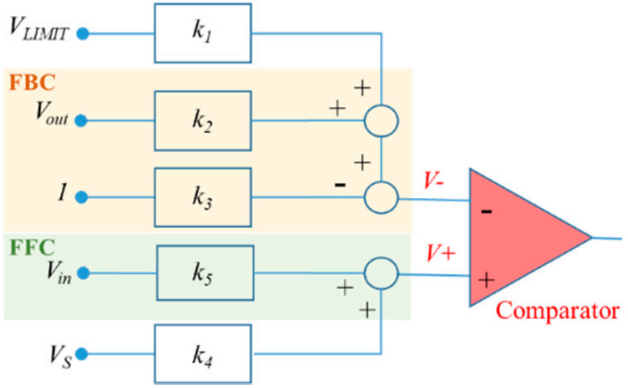

(b)

Figure 6. Control block diagrams of the traditional peak current mode control PWM (a) and the proposed CPC-PWM (b).

Design Example:

In order to verify the feasibility of the proposed CPC-PWM, a $5 \mathrm{~W}$ prototype is designed and realized. The specifications and circuit diagram of the prototype are listed and shown in Table 1 and Figure 7, respectively.

Table 1. Specifications of the realized prototype.

\begin{tabular}{cc}
\hline Specification & Value \\
\hline Input voltage & $17 \sim 34 \mathrm{~V}$ \\
\hline Output voltage & $5 \mathrm{~V}$ \\
\hline Output current & $1 \mathrm{~A}$ \\
\hline Ripple voltage & $30 \mathrm{mV}$ \\
\hline Output power & $5 \mathrm{~W}$ \\
\hline Overcurrent point & $1.3 \mathrm{~A} \pm 2 \%$ \\
\hline Switching frequency & $550 \mathrm{kHz}$ \\
\hline
\end{tabular}

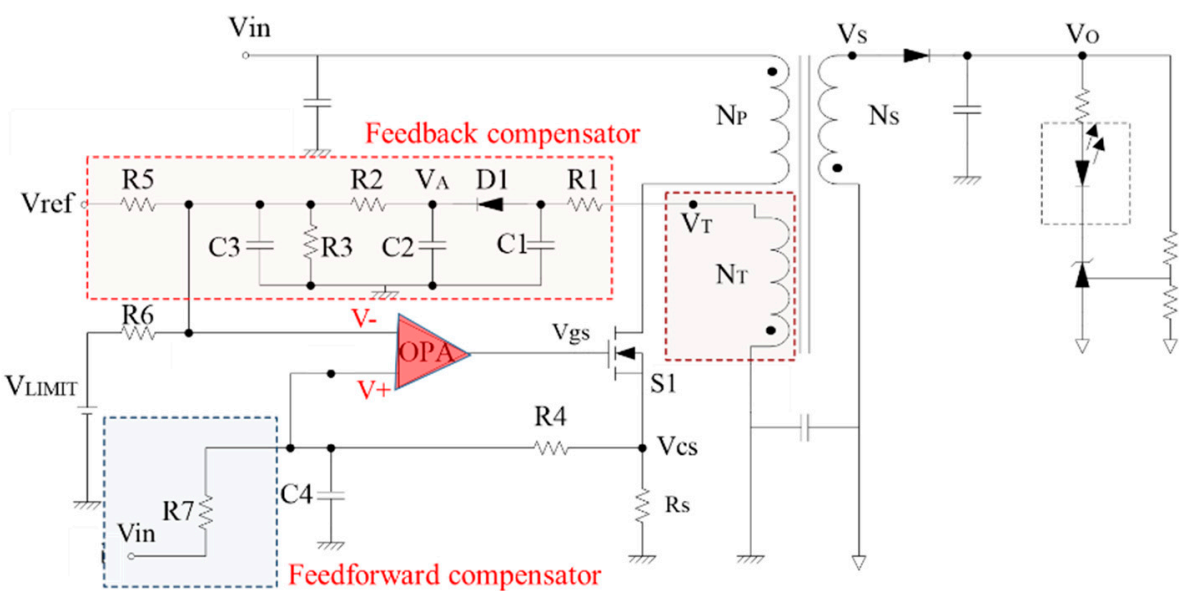

Figure 7. Circuit diagram of the proposed compensated peak current mode controlled PWM method.

The flyback converter proposed in this paper is mainly constructed by a transformer, an FBC, an FFB, and a power switch $S 1$ as shown in Figure 7. The transformer includes a primary winding, a secondary winding, and an auxiliary winding or third winding. The output voltage of the third winding is injected into the feedback compensator circuit to adjust the PWM duty of the power switch. FBC is composed of a diode $D 1$, four resistors $R 1, R 2, R 3$, and $R 5$, and three capacitors $C 1, C 2$, and $C 3$, as shown as a red block in Figure 7 . Due to the characteristics of the flyback converter, the energy is transferred to the secondary 
side when the power switch is turned off. At the same time, the third winding is used to sample the output voltage condition to obtain the voltage $V_{T}$. Due to the transformer leakage inductance, there will be a spike voltage and the voltage $V_{A}$ can be obtained only after being processed by a low-pass filter. A first-order RC filter is used and meet to (9) to filter out spike voltage

$$
R 1 \cdot C 1 \geq t_{\text {spike }}
$$

where $t_{\text {spike }}$ is the period of the spike voltage.

The feedback compensator is a network circuit and can be simplified as Figure 8 . The simplified circuit is composed of three voltage sources $V_{A}, V_{\text {ref }}$, and $V_{\text {LIMIT }}$, and four resistors $R 2, R 3, R 5$, and $R 6$. Voltage $V$ - can be obtained and shown as (10) by using KCL law. Compared with (5), parameters $k_{1}, k_{2}$, and $k_{3}$ can be obtained and shown as (11)-(13).

$$
V-=\frac{V_{r e f} \cdot G_{5}+V_{L I M I T} \cdot G_{6}+V_{A} \cdot G_{3}}{\left(G_{5}+G_{6}+G_{3}+G_{2}\right)}
$$

where $G_{X}$ is the reciprocal of $R_{X}$, that is a conductance.

$$
\begin{gathered}
k_{1}=\frac{G_{6}}{\left(G_{5}+G_{6}+G_{3}+G_{2}\right)} \\
k_{2}=-\frac{n_{3} \cdot G_{3}}{n_{2} \cdot\left(G_{5}+G_{6}+G_{3}+G_{2}\right)} \\
k_{3}=\frac{V_{r e f} \cdot G_{5}}{\left(G_{5}+G_{6}+G_{3}+G_{2}\right)}
\end{gathered}
$$

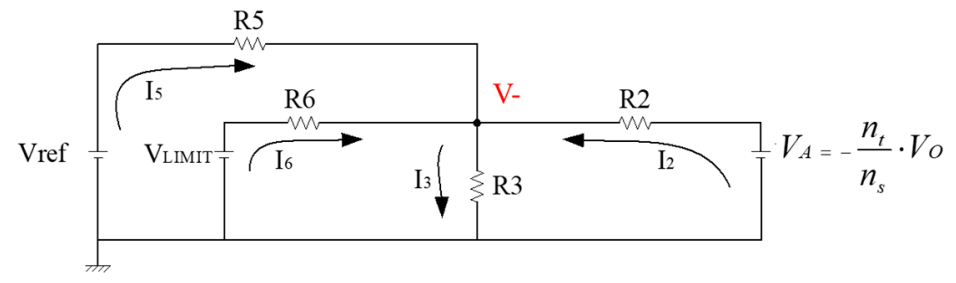

Figure 8. Simplified FBC circuit.

The FFC is a network circuit composed of two voltage sources $V_{\text {in }}$ and $V_{s}$, and two resistors $R 4$ and $R 7$. Voltage $V+$ can be obtained and shown as (14) by using KCL law. Compared with (7), parameters $k_{4}$ and $k_{5}$ can be obtained and shown as (15) and (16). In addition, the relation between resistor $R 4$ and $R 7$ is shown as (17).

$$
V+=\frac{V_{i n} \cdot G_{7}+V_{S} \cdot G_{4}}{\left(G_{7}+G_{4}\right)}
$$

where $G_{X}$ is the reciprocal of $R_{X}$, that is a conductance.

$$
\begin{gathered}
k_{4}=\frac{G_{4}}{\left(G_{7}+G_{4}\right)} \\
k_{5}=\frac{G_{7}}{\left(G_{7}+G_{4}\right)} \\
R_{7}=\frac{R_{4} \cdot L_{P}}{t_{\text {delay }} \cdot R_{S}}-R_{4}
\end{gathered}
$$

The used components of the designed flyback converter as shown in Figure 7 are listed in Table 2. 
Table 2. The used components and parameters in the design example.

\begin{tabular}{cccc}
\hline Parts & Value & Parts/Parameters & Value \\
\hline Resistor R1 & $1.1 \mathrm{~K} \Omega$ & Capacitor C1 & $47 \mathrm{pF}$ \\
\hline Resistor R2 & $34 \mathrm{~K} \Omega$ & Capacitor C2 & $470 \mathrm{pF}$ \\
\hline Resistor R3 & $2.43 \mathrm{~K} \Omega$ & Capacitor C3 & $10 \mathrm{nF}$ \\
\hline Resistor R4 & $1 \mathrm{~K} \Omega$ & Capacitor C4 & $33 \mathrm{pF}$ \\
\hline Resistor R5 & $73.2 \mathrm{~K} \Omega$ & Volatge Vref & $5.2 \mathrm{~V}$ \\
\hline Resistor R6 & $100 \mathrm{~K} \Omega$ & Volatge V VIMIT & $0.5 \mathrm{~V}$ \\
\hline Resistor R7 & $290 \mathrm{~K} \Omega$ & Volatge Vfault & $0.385 \mathrm{~V}$ \\
\hline Resistor RS & $0.15 \Omega$ & & \\
\hline
\end{tabular}

\section{Experimental Results}

The feasibility and superiority of the proposed method are verified by discussing and comparing "overload current variation", "input power consumption during short circuit" and "overflow current variation".

Figure $9 \mathrm{a}-\mathrm{c}$ shows the V-I curves obtained by using the traditional peak current control. Figure $9 \mathrm{~d}-\mathrm{f}$ shows the V-I curves obtained by using the proposed FBC method.

It can be seen from Figure $9 \mathrm{a}-\mathrm{c}$ that the V-I curve has an obvious relationship with the input voltage $V_{\text {in }}$. When the input voltage $V_{\text {in }}$ is higher, the overload point will also be higher. Figure $9 \mathrm{~d}-\mathrm{f}$ shows the V-I curves obtained using the proposed FBC method. It can be seen that when the input voltage $V_{\text {in }}$ changes from $17 \mathrm{~V}$ to $34 \mathrm{~V}$, there is no significant difference in the output current changes. It indicates that the proposed FBC method is significantly better than the traditional peak current control. From Figure $9 \mathrm{~d}-\mathrm{f}$, we can also see that the output current during overload can be suppressed effectively by the proposed FBC as the theory predicted.

Figure 10a shows the comparison results of the measured overload point current using the traditional peak current control and the proposed FBC method. The variation rate of overload point current under different input voltages of the proposed FBC method is about $2 \%$ far better than the traditional $34.5 \%$. In this design example, the traditional method requires at least a diode with a $1.7 \mathrm{~A}$ current stress. However, the proposed FBC method only needs a diode with 1.3 A current stress. Figure $10 \mathrm{~b}$ shows the comparison results of the measured input power consumption using the traditional peak current control and the proposed FBC method under the output short circuit condition. Moreover, Figure 11b shows that the input power consumption of the proposed method under short-circuit protection is far superior to the traditional method. This means that there is no need to choose a power component with a larger current rating. In this way, the power consumption problem caused by the overload or short-circuited can be suppressed, and the components with larger specifications can be avoided.

Figure 11a-f shows the experimental waves under different input voltages of $17 \mathrm{~V}$, $28 \mathrm{~V}$, and $34 \mathrm{~V}$ when the flyback converter with/without FFC. In these figures, the positive terminal input voltage $V+$ of the comparator, the negative terminal input voltage $V$ - of the comparator, and the output voltage Vout waveforms of the flyback converter are shown. It can be seen from Figure 11a-c that without using FFC, the voltage $V$ - starts to climb from zero voltage under various input voltages. Until voltage $V-$ is greater than voltage $V+$, the power switch is turned off after the time $t_{\text {delay }}$. Observing the $V$ - waveform, it can be seen that the input voltage $V_{\text {in }}$ is larger and the overflow current $\Delta I_{P}$ is larger. From Figure $11 \mathrm{~d}-\mathrm{f}$, can be seen that an offset voltage is injected into $V-$, so that the overflow current $\Delta I_{P}$ is suppressed. The injected voltage is about $51 \mathrm{mV}, 90 \mathrm{mV}$, and $105 \mathrm{mV}$ when the input voltage is $17 \mathrm{~V}, 28 \mathrm{~V}$, and $34 \mathrm{~V}$, respectively. According to the experimental results, the proposed method is close to the expected theoretical result. The voltage injected by 
different input voltages will also be different, which can reach the $V+$ voltage early to achieve the purpose of effectively reducing the overflow current $\Delta I_{P}$.

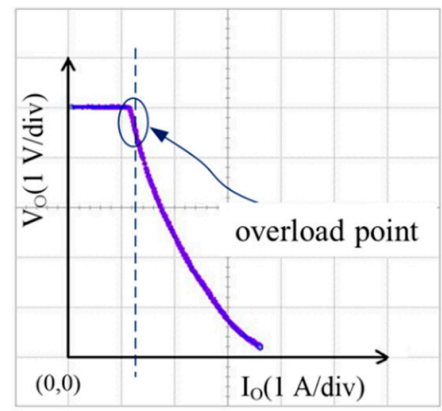

(a)

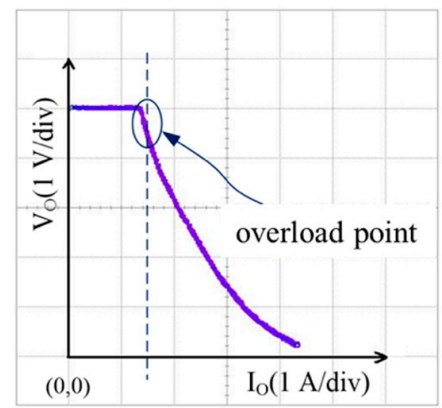

(b)

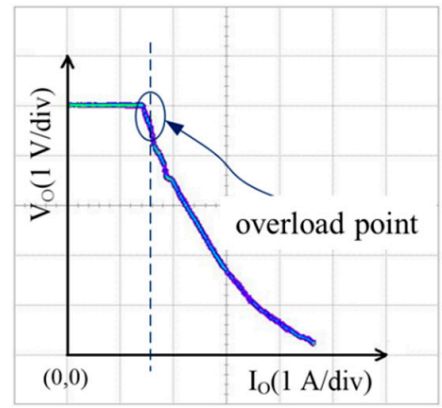

(c)

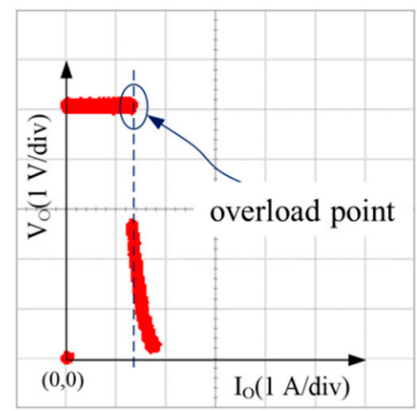

(d)

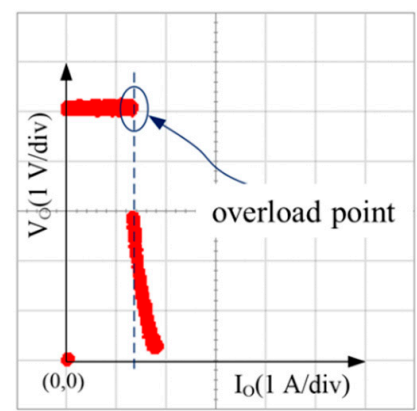

(e)

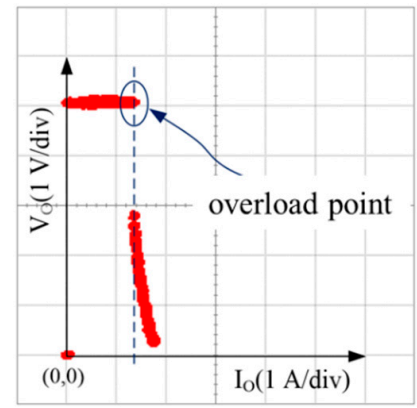

(f)

Figure 9. V-I curves obtained by using the traditional peak current detection circuit with input voltage (a) $17 \mathrm{~V}$, (b) $18 \mathrm{~V}$, and (c) $34 \mathrm{~V}$, and by using the proposed FBC method with input voltage (d) $17 \mathrm{~V},(\mathbf{e}) 18 \mathrm{~V}$, and (f) $34 \mathrm{~V}$.

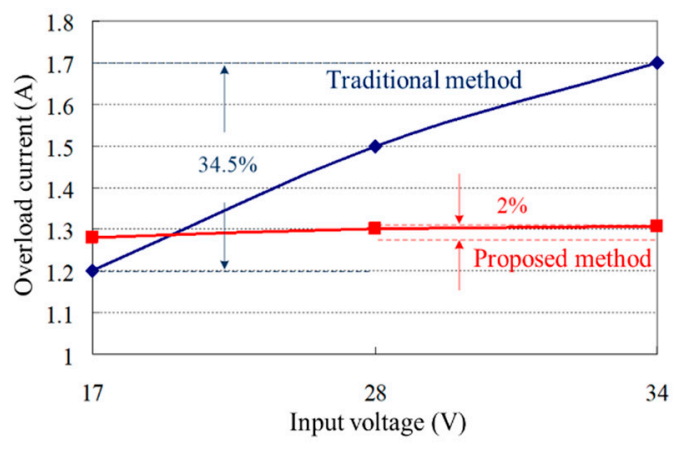

(a)

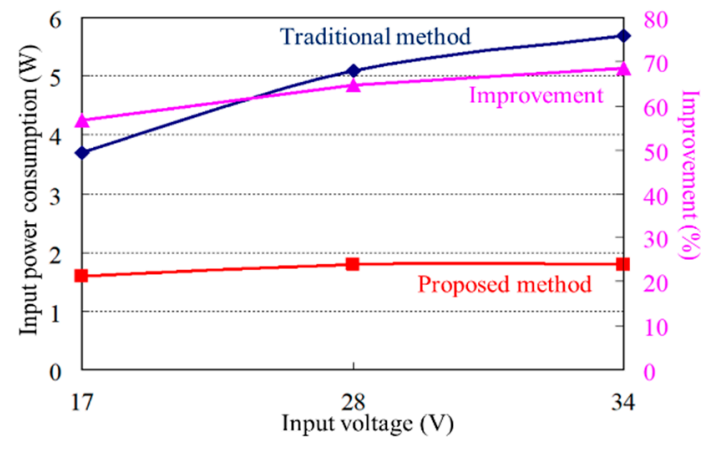

(b)

Figure 10. Experimental results (a) Overload current under different input voltage, (b) Input power consumption under different input voltage. 


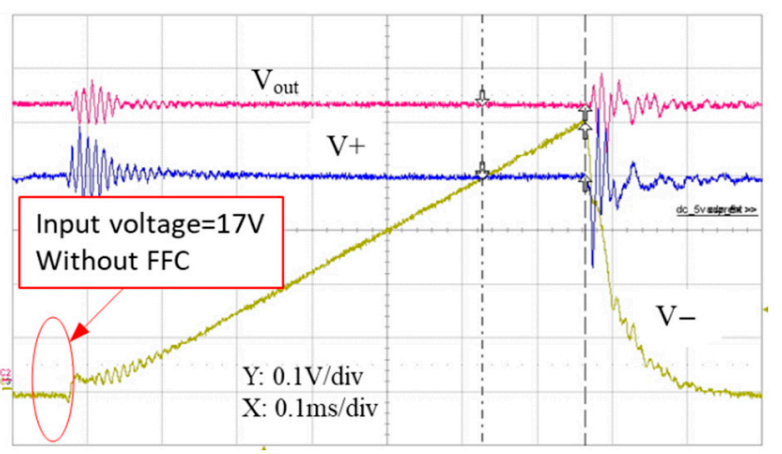

(a)

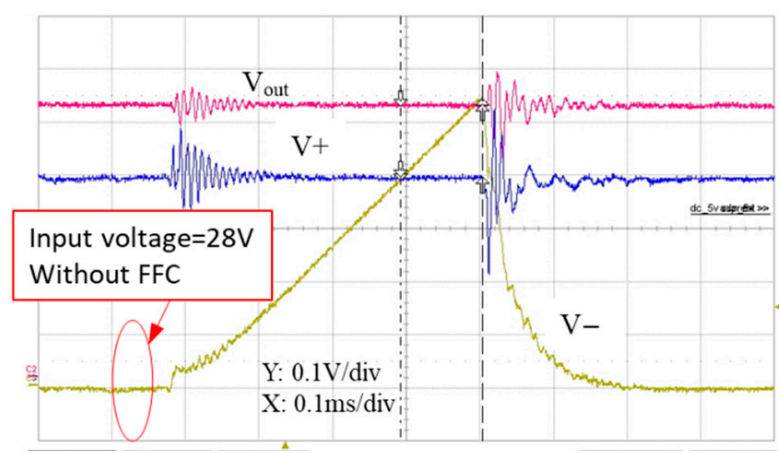

(b)

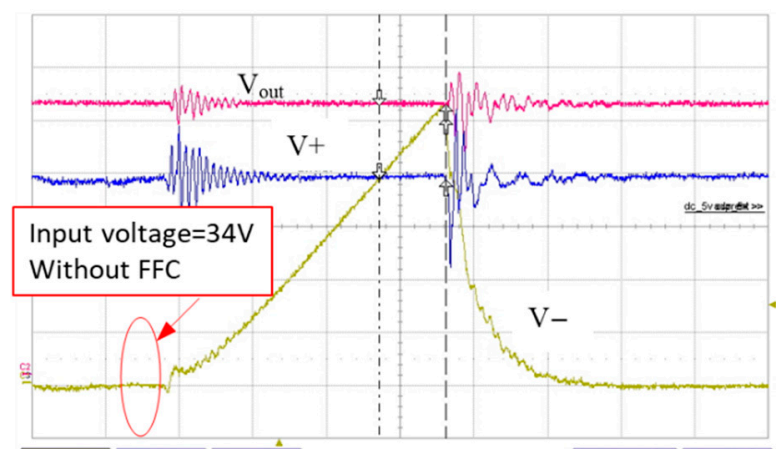

(c)

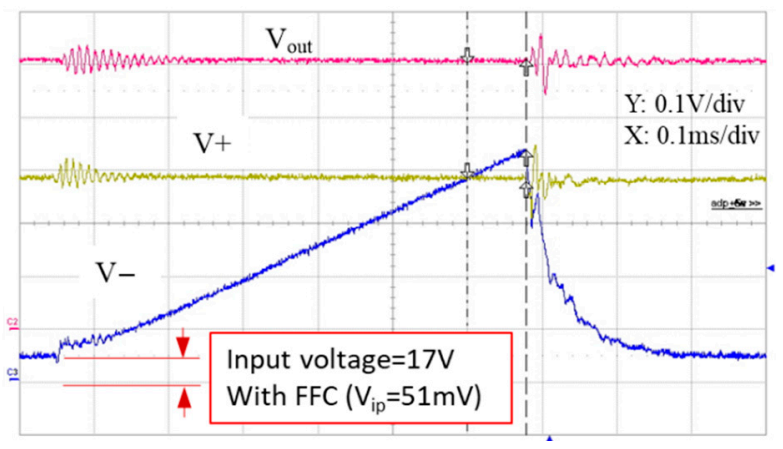

(d)

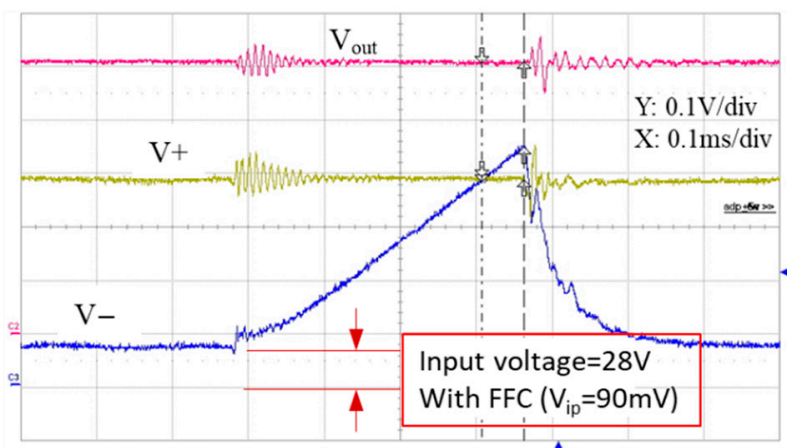

(e)

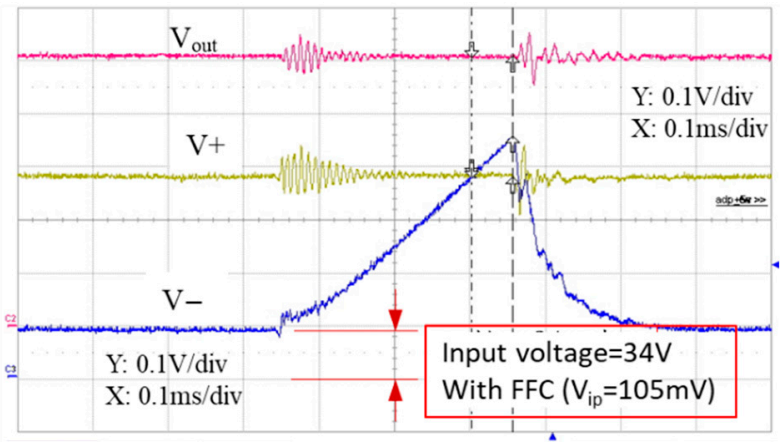

(f)

Figure 11. $V-, V+$, and Vout curves obtained by using the traditional peak current detection circuit with input voltage (a) $17 \mathrm{~V}$, (c) $18 \mathrm{~V}$, and (e) $34 \mathrm{~V}$, and by using the proposed FFC with input voltage (b) $17 \mathrm{~V}$, (d) $18 \mathrm{~V}$, and (f) $34 \mathrm{~V}$.

It is known that different voltage levels are required for different input voltages to be injected in the proposed FFC. From the experimental results, the accuracy of the $\mathrm{V}_{\mathrm{CS}}$ is still not enough. If we can analyze the characteristics of the control IC, such as the $t_{\text {delay }}$ time of different voltages, it will help the FFC to be more accurate. On the other hand, the circuits of the proposed CPC-PWM can be digitalized and simplified. For example, a small Micro-controller can be used to replace the proposed circuit, which will contribute to its simple structure, accuracy, and flexibility.

\section{Conclusions}

In this paper, a feedback compensator (FBC) and a feedforward compensator (FFC) were successfully proposed to construct a novel Compensated Peak Current mode control PWM (CPC-PWM) for primary-side controlled flyback converters. The relevant theories and methods proposed in this paper have been confirmed by circuit implementation. A $5 \mathrm{~W}$ prototype with a wide input range has been designed and realized to access system performance. Using the proposed FBC, the PWM duty of a flyback converter working in 
overload can be descended to limit the current. The power consumption problem caused by the overload or short-circuited can be suppressed, and the components with larger specifications can be avoided. Using the proposed FFC, the effect of delay time can be descended to reduce the overflow current. The experimental results show that the proposed CPC-PWM can validate in a wide input voltage range and output short conditions, which also has good current accuracy and reduces power dissipation by about $68 \%$.

Author Contributions: Conceptualization, C.-H.W., G.-R.H. and L.-R.C.; methodology, C.-H.W.; software, G.-R.H.; validation, C.-H.W. and L.-R.C.; formal analysis, C.-H.W., G.-R.H. and L.-R.C.; investigation, G.-R.H. and L.-R.C.; resources, C.-C.C.; data curation, C.-H.W. and C.-C.C.; writing-original draft preparation, C.-H.W., G.-R.H. and C.-C.C.; writing-review and editing, C.-C.C., C.-M.L. and L.-R.C.; visualization, C.-C.C., C.-H.W. and C.-M.L.; supervision, L.-R.C. All authors have read and agreed to the published version of the manuscript.

Funding: This research received no external funding.

Institutional Review Board Statement: Not applicable.

Informed Consent Statement: Not applicable.

Data Availability Statement: Not applicable.

Conflicts of Interest: The authors declare no conflict of interest.

\section{References}

1. Liang, T.J.; Chen, K.H.; Chen, J.F. Primary side control for flyback converter operating in DCM and CCM. IEEE Trans. Power Electron. 2017, 33, 3604-3612. [CrossRef]

2. Cheng, M.C.; Pan, C.T.; Teng, J.H.; Luan, S.W. An Input Current Ripple-Free Flyback-Type Converter With Passive Pulsating Ripple Canceling Circuit. IEEE Trans. Ind. App. 2017, 53, 1210-1218. [CrossRef]

3. Connaughton, A.; Talei, A.P.; Leong, K.K.; Krischan, K.; Muetze, A. Investigation of a soft-switching flyback converter with full secondary side-based control. IEEE Trans. Ind. Applicat. 2017, 53, 5587-5601. [CrossRef]

4. Yaqoob, S.J.; Obed, A.; Zubo, R.; Al-Yasir, Y.I.A.; Fadhel, H.; Mokryani, G.; Abd-Alhameed, R.A. Flyback Photovoltaic MicroInverter with a Low Cost and Simple Digital-Analog Control Scheme. Energies 2021, 14, 4239. [CrossRef]

5. Connaughton, A.; Talei, A.P.; Leong, K.K.; Krischan, K.; Muetze, A. Variable on-time control scheme for the secondary-side controlled flyback converter. IEEE Trans. Power Electron. 2018, 34, 2416-2426. [CrossRef]

6. Marroquín-Arreola, R.; Salazar-Pérez, D.; Ponce-Silva, M.; Hernández-De León, H.; Aquí-Tapia, J.A.; Lezama, J.; SaavedraBenítez, Y.I.; Escobar-Gómez, E.N.; Lozoya-Ponce, R.E.; Mota-Grajales, R. Analysis of a DC-DC Flyback Converter Variant for Thermoelectric Generators with Partial Energy Processing. Electronics 2021, 10, 619. [CrossRef]

7. Kumar, R.; Wu, C.-C.; Liu, C.-Y.; Hsiao, Y.-L.; Chieng, W.-H.; Chang, E.-Y. Discontinuous Current Mode Modeling and Zero Current Switching of Flyback Converter. Energies 2021, 14, 5996. [CrossRef]

8. Yau, Y.-T.; Hwu, K.-I.; Liu, K.-J. AC-DC Flyback Dimmable LED Driver with Low-Frequency Current Ripple Reduced and Power Dissipation in BJT Linearly Proportional to LED Current. Energies 2020, 13, 4270. [CrossRef]

9. Adragna, C.; Gritti, G.; Raciti, A.; Rizzo, S.A.; Susinni, G. Analysis of the Input Current Distortion and Guidelines for Designing High Power Factor Quasi-Resonant Flyback LED Drivers. Energies 2020, 13, 2989. [CrossRef]

10. Ponce-Silva, M.; Salazar-Pérez, D.; Rodríguez-Benítez, O.M.; Vela-Valdés, L.G.; Claudio-Sánchez, A.; De León-Aldaco, S.E.; CortésGarcía, C.; Saavedra-Benítez, Y.I.; Lozoya-Ponce, R.E.; Aquí-Tapia, J.A. Flyback Converter for Solid-State Lighting Applications with Partial Energy Processing. Electronics 2021, 10, 60. [CrossRef]

11. Hannan, M.A.; Hoque, M.M.; Ker, P.J.; Begum, R.A.; Mohamed, A. Charge Equalization Controller Algorithm for Series-Connected Lithium-Ion Battery Storage Systems: Modeling and Applications. Energies 2017, 10, 1390. [CrossRef]

12. Dimitrov, B.; Krishna, M.; Cruden, A.; Sharkh, S.; Elkhateb, A. Analysis, Design, and Experimental Validation of a Primary Side Current-Sensing Flyback Converter for Use in a Battery Management System. Electronics 2018, 7, 43. [CrossRef]

13. Zhang, X.; Min, R.; Zhang, D.; Wang, Y. An Optimized Sensorless Charge Balance Controller Based on a Damped Current Model for Flyback Converter Operating in DCM. Energies 2018, 11, 3478. [CrossRef]

14. Liu, X.; Sun, Y.; He, Y.; Zheng, X.; Zeng, G.; Zhang, J. Battery Equalization by Fly-Back Transformers with Inductance, Capacitance and Diode Absorbing Circuits. Energies 2017, 10, 1482. [CrossRef]

15. Cao, Y.; Li, K.; Lu, M. Balancing Method Based on Flyback Converter for Series-Connected Cells. IEEE Access 2021, 9, 52393-52403. [CrossRef]

16. Cao, J.; Xia, B.; Zhou, J. An Active Equalization Method for Lithium-ion Batteries Based on Flyback Transformer and Variable Step Size Generalized Predictive Control. Energies 2021, 14, 207. [CrossRef]

17. Wang, C.; Xu, S.; Lu, S.; Sun, W. A low-cost constant current control method for DCM and CCM in digitally controlled primary-side regulation flyback converter. IEEE Trans. Emerg. Sel. Top. Power Electron. 2017, 6, 1483-1494. [CrossRef] 
18. Lee, Y.J.; Niou, C.P.; Chen, C.Y.; Tsai, C.H. A digital power factor controller for primary-side-regulated LED driver. IEEE Access 2020, 8, 21813-21822. [CrossRef]

19. Chen, M.; Xu, S.; Huang, L.; Sun, W.; Shi, L. A novel digital control method of primary-side regulated flyback with active clamping technique. IEEE Trans. Circuits Syst. I Regul. Pap. 2020, 68, 950-962. [CrossRef]

20. Wang, C.; Sun, D.; Zhang, X.; Hu, J.; Gu, W.; Gui, S. A Constant Current Digital Control Method for Primary-Side Regulation Active-Clamp Flyback Converter. IEEE Trans. Power Electron. 2020, 36, 7307-7318. [CrossRef]

21. Huang, P.L.; Chen, D.; Chen, C.J.; Chen, Y.M. An adaptive high-precision overpower protection scheme for primary-side controlled flyback converters. IEEE Trans. Power Electron. 2011, 26, 2817-2824. [CrossRef]

22. Zhu, Z.; Wu, Q.; Wang, Z. Self-compensating OCP control scheme for primary-side controlled flyback AC/DC converters. IEEE Trans. Power Electron. 2016, 32, 3673-3682. [CrossRef]

23. Han, Y.; Wu, Q.; Li, Y.; Zhu, Z. Average inductor current measure and control strategy for multimode primary-side flyback converters. IEEE Trans. Power Electron. 2020, 35, 13096-13103. [CrossRef]

24. Li, Y.; Zhu, Z. A constant current control scheme for primary-side controlled flyback controller operating in DCM and CCM. IEEE Trans. Power Electron. 2020, 35, 9462-9470. [CrossRef]

25. Wu, Q.; Zhu, Z. An Adaptive High-Precision OCP Control Scheme for Flyback AC/DC Converters. IEEE Trans. Power Electron. 2017, 32, 8969-8973. [CrossRef]

26. Sato, T.; Nakano, T.; Harada, K. The overload-protection characteristics of the current-mode DC-to-DC converter: Analysis and improvement. In Proceedings of the 19th Annual IEEE Power Electronics Specialists Conference, Kyoto, Japan, 11-14 April 1988; pp. 830-835.

27. AN-6754A-Design Guideline to Replace SG6742 with FAN6754A, Version 1.0.1; Fairchild Semiconductor: Sunnyvale, CA, USA, 2013. Available online: https:/ / www.onsemi.com/pub/Collateral/AN-6754A.pdf (accessed on 23 November 2020). 